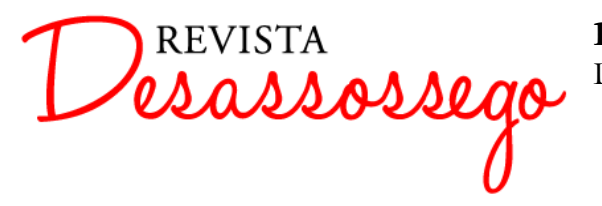

\title{
MEMÓRIAS DO FUTURO PASSADO: a história de um horizonte desejado
}

Leonardo Lima Ribeiro ${ }^{1}$

\begin{abstract}
Sade e Céline esforçaram-se, com maior ou menor felicidade, por tornar quase barrocos seus fantasmas negativos. Por essa razão, eles deveriam ser considerados como autores-chave de uma ecologia mental. Na falta de uma tolerância e de uma inventividade permanente para "imaginarizar" os diversos avatares da violência, a sociedade corre o risco de fazê-los cristalizarse no real. [...] Por todos os meios possiveis, trata-se de conjurar o crescimento entrópico da subjetividade dominante. Em vez de ficar perpetuamente ao sabor da eficácia falaciosa de challenges econômicos, trata-se de se reapropriar de Universos de valor no seio dos quais processos de singularização poderão reencontrar consistência.
\end{abstract}

Félix Guattari, As Três Ecologias

Pressupor a dor como processo imanente aos nossos mecanismos biológicoafetivos é, possivelmente, intuir o não-esquecimento de circuitos vivos que nos esmagam à realidade. Esta dor, ao que parece, permanece circunscrita nos limites infinitesimais dos gritos do mundo ensanguentado, um grilhão que sangra não porque nos atura, mas porque está à altura da própria tarefa: depravar-se. Assim, talvez sejamos excessivamente mundo, assomados, portanto, à expressão da anunciada tarefa que lhe pertence. Tão mundanos somos que, conquanto também humanos, mundanos ainda sejamos, às margens crônicas e irregulares do real que não apenas se amordaça, mas nos admite em sua foz, num lugar do qual grunhimos autopunição.

Seríamos assassinos uns dos outros e do mundo, sob a mediação do ódio de vítimas contingencialmente necessário que segue da dor e das tristezas, ou, contrariamente, encarnaríamos o papel de suicidas fraternos ao real, cuja fisionomia é gestada no teatro o qual toma a morte como palco? Talvez um pouco, ou bastante, das duas coisas: suicidas e homicidas deformados pelas dores. Está nisto então o pano de fundo do que apelidamos de amor? É provável. E do trabalho e seus frutos, tais como cidades, regimes jurídicopolíticos e Estados Nacionais? É possível. E do futuro? É possível.

\footnotetext{
1 Possui graduação em Comunicação Social pela Universidade de Fortaleza (UNIFOR); é especialista em Teorias da Comunicação e da Imagem pela UFC (Universidade Federal do Ceará); é mestre em filosofia (linha de pesquisa: Ética) pela UECE (Universidade Estadual do Ceará). É autor do livro Ciência Intuitiva e Suprema Liberdade na Ética de Spinoza [2013].
} 


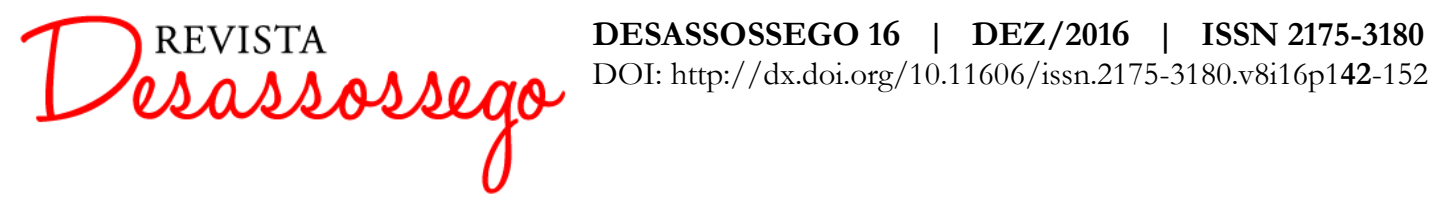

A [auto]destrutiva dor de homens e mulheres, expressão rebatida no mundo que é já gemido, confere ao amor a alegria plural amiúde incipiente: cínica consistência dinâmica que percorre como espectro da morbidez a superfície das cidades. Estas, sustentadas como palafitas pelos rios de sofrimento que intentam fazer calar, decerto se debatem com o que há de vivo deste morto mundano: o sofrimento e a dor das quais apenas na aparência bradam o enterro. O defunto não se amedronta. É a intensa origem de frágeis substâncias, como o gáudio e beligerantes Estados Nacionais, não podendo ser sonegado pelos fluxos do dinheiro, impérios multinacionais e fragmentos de presentes formas de vida. Como passado histórico, espoliado por dissimulação, o finado é astuto futuro, por muitos sendo horizonte desejado. Estaríamos dispostos a admitir a história real desse futuro que, apesar de exprimir-se como injunção, com prazer relegamos às costas da vida, enterrando-o à espessura de convicto esquecimento?

Quando nos alegramos conosco enquanto narcisos em expansão, parece que o mundo, por seu lado, transmuta-se numa espécie de sócio minoritário da inebriante felicidade. Esse júbilo, como parte do mundo, converte-se então nas parcelas de escárnio quando, de forma estrita, é recoberto pelos costumes de fisionomia humana; este escárnio, que também debocha de si na carnavalesca felicidade, constrói caricato personagem, cimentando processos do sofrido mundo orgânico, o qual, por seu lado e no limite, é o primeiro ator a travestir euforia com os espinhos da dor. Muitas das alegrias dos homens são então ardis da indiferença. Esta violência passiva é imanente aos sorrisos, redesenhados para escondermos a infinitude das agonias e dissabores. Os sorrisos mascarados, em sua maioria, são secreção direcionada para agudas investidas que, sendo veredicto da vileza, ou seja, o transe dos transeuntes, naturalizam-se nos bairros e cidades como egos iluminados.

Não se trata, assim, de inocentarmos a natureza, mas de insinuar que, no fundo, com hábitos torpes, asseguramos à nossa maneira opressões da dissimulada alegria humana sobre um planeta o qual acolhe calafrios e se encolhe num gulag como pária. Disto, atesta-se o recalque apátrida que está na iminência de retornar na forma de errante revés, talhando movimentos num avanço persecutório radical, como guilhotina objetivando fazer rolar as cabeças autodenominadas de bondosas e amorosas, na espessura dos rostos maquiados, que disfarçam sorrateiramente de seu tecido o bojo, mas não por longo tempo.

Todavia, bolsas ondulantes, ou os calos das olheiras por debaixo dos estéreis disfarces das alegrias cotidianas, atestam insônia. Esta insônia é pautada pelo medo de 


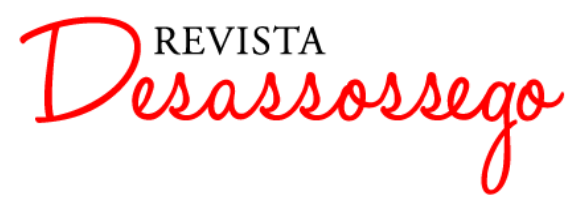

DESASSOSSEGO 16 | DEZ/2016 | ISSN 2175-3180

DOI: http://dx.doi.org/10.11606/issn.2175-3180.v8i16p142-152

sermos arrancados, a qualquer momento, das vestes orgânicas; receio também do que poderá se desdobrar na insurgência contra a fachada do peito, que é decerto a rebelião contra o risível das aparências incriminadas. É a guerrilha do sensível que opera frente ao tórax, afetos os quais, nos arrastando ao recortar por dentro a superfície da carne num avanço transversal, fazem intuir que as origens da pele antes estavam, e sempre estiveram, assentadas no abismo de um caos. É este que, por seu lado, irá promover o fundo do poço, sendo novamente apresentado na forma de boca ressequida e, precipuamente, de cicatrizes ou bordas de amarelados gracejos oxidados. Aqui, a gargalhada perde sua força em função do retorno delirante de algo estranho aos lábios e, entrementes, os opacos olhos correspondentes também terminam por extraviar a falta de brilho que a eles já pertencia.

A relação entre os ardis da sorridente boca e a opacidade do olhar matreiro sempre me pareceu bastante estreita e assustadora. Quando a conexão entre ambos é realmente garantida, como maneira de agraciar o fato de que o real do mundo deva ser cambiado pelas espertezas das alegorias da rostidade alegremente comercializada pelos espaços civis, tenho a impressão de que não há outro caminho na relação boca impudente e olho opaco que não o de uma breve derrocada - conexão passível de ser substituída pelos golpes de uma maldade ainda maior, proveniente daquilo que esta mesma boca e olhar boicotaram na sequência das próprias vidas, focadas estritamente no desprezo da gênese.

Afinal de contas, o desdém da gênese é uma espécie de negligência que me parece pouco relativa na agudeza, caso observemos com maior depuração o modo como nos colocamos no telos do trabalho para outrem e dos investimentos cotidianos em nós mesmos, espalhando-nos como herdeiros de relações sociais, à superfície das cidades. $\mathrm{O}$ que é viver e trabalhar numa cidade precisa? Como com ela nos relacionamos sob apoio dos pares, que em nós também se apoiam, como se atestassem a paisagem de fortes guarnecidos de aconchego? A dissimulada esperança, voltada não só às alegrias do mercado, mas às relações de trabalho, não é justamente a topologia de uma confortável zona que está sustentada nos pilares do desconforto, imanente à temeridade do esgotamento da própria existência? Não quererá, por seu lado, esse mundo tudo implodir, a despeito das esperanças dos narcisos que nos tornamos, personagens épicos que mal suportam conviver uns com os outros? $\mathrm{O}$ animal político de Aristóteles não teria historicamente se transmutado em metafísico humano, que se acredita livre sobre uma natureza que lhe serve de justo alento, tal como se andasse com plataformas de aço para 


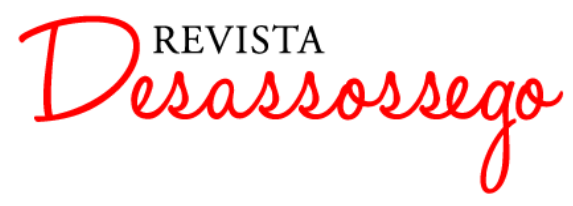

DESASSOSSEGO 16 | DEZ/2016 | ISSN 2175-3180

DOI: http://dx.doi.org/10.11606/issn.2175-3180.v8i16p142-152

melhor fazer a Terra gritar e sem esquecer, nesse sonoro compasso, do empinado nariz, a encarnação de um orgulhoso desprezo que só denuncia o quão perto da guilhotina voraz está? Não mereceria ele, por tal afã, ser arrancado das esferas da realidade, observando, caso ainda possa, o quanto de seu asno e galanteador sorriso ainda se conservará?

Muitos dos nossos estão convencidos de que o trabalho como forma de expressão humana é algo sacrossanto, porquanto há, por meio dele, a perpetuação de nossa espécie e o desenvolvimento subsequente da linguagem como diferentes maneiras de colocar, no arremedo das sociedades arquitetadas, cultura. Este trabalho como intervenção do homem sobre as matérias mundanas, tanto quanto do homem sobre o próprio homem, é avaliado respectivamente tanto de um ponto de vista material (intervenção sobre o mundo) quanto de uma perspectiva imaterial (linguagem/cultura/educação): um norte fundamental com o qual nossos desejos mais sinceros devem se relacionar. Assim, transformar como homens a matéria do mundo em sua passividade, relativamente aos "protagonistas" do planeta, não é o único objeto de desejo coerente com a espécie humana, já que a tradição da prescrição da transformação do mundo pelo homem (que nesse compasso se transforma) deve ser instrumento de cultura, de educação, da prole arrebanhada para o trabalho porvir.

Hodiernamente, esse processo é mediado em parte pela noção de salário, uma vez que não há trabalho contratualmente legal que não esteja virtualmente expresso como preço (a ser realizado na forma dinheiro). Isso atesta finalmente o fato histórico de que o trabalho como ascese paulatina do homem sobre o mundo em movimento inverso (aparentemente temerário), tem sua arte delimitada não apenas quando quer se apresentar como modo humano de domínio sobre o mundo material e modo de produção de linguagem como instrumento pedagógico para reprodução de domínio. Hoje em dia, o trabalho é, em sua forma majoritária, assalariado, uma obviedade relativamente recente, e que pressupõe há algum tempo a relação contratual patrão-empregado: expressa como segredo não tão oculto do fato de que alguns homens deixam de trabalhar sobre o mundo para colocar sob sua tutela outros (antigos escravos alforriados e sua prole, tanto quanto o planeta e as tecnologias da sociedade da informação), os quais para eles possam legalmente trabalhar sob o regime intensivo e flexível de espólios juridicamente velados, subsumidos e regulados pelos Estados Nacionais. Um ardil que não ocorria em economias políticas anteriores, como era o caso do feudalismo. 


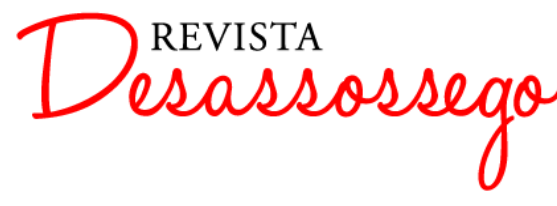

DESASSOSSEGO 16 | DEZ/2016 | ISSN 2175-3180

DOI: http://dx.doi.org/10.11606/issn.2175-3180.v8i16p142-152

Assim, alguns homens, aqueles que não trabalham (porquanto são herdeiros das riquezas extraídas do planeta e de escravos há séculos) passam a intensificar por meio de outros homens, mulheres e crianças (o século XIX é um dos grandes marcos disso) o domínio sobre a totalidade do mundo. Mas não só: homens, mulheres e crianças que trabalham também estão sob o domínio de um conjunto minoritário de comparsas, assomados às contemporâneas multinacionais e ao aporte de Estados Nacionais militarizados, com parlamentos e congressos de honestidade contestável.

O mundo do consumo e dos narcisos que se autoconsomem por gozarem uns dos outros na forma esdrúxula dos escárnios não deixa de ser uma ferramenta contemporânea que retroalimenta o vampirismo "bazófico" dos que não trabalham sobre os que trabalham. De todo modo, também se deixam emaranhar pelo tecido do excessivo mercado, que é visto como prática altamente democrática, simulação expandida inclusive àqueles que antes nada tinham, senão a própria força de trabalho, ausente de riquezas materiais e de maiores investimentos intelectuais, conquanto dinâmicos, "competentes", "flexíveis" e eficazes para exercerem a "cidadania" de um labor - garantia do pão na dança macabra do circo consumista dos civis (de classe média ou não), recobertos pela empáfia do neocanibalismo.

Ora, essa narrativa não é plenamente válida para o que aqui está em jogo. O que estávamos a expor desde o exórdio deste escrito é que o sujeito de nossa história é o mundo, que confere para si a própria guilhotina, e coloca os seus desdobramentos, isto é, suas crias, sob o temor da autopunição. Ficando isto evidenciado, adiante precisamos nos desembaraçar dos defeitos de muitas das defesas compassivas do homem, um juiz a favor da humanidade do homem, estritamente fraterno a uma dinâmica afetiva narcísica, a de ser humano, o que tem efeitos em alguns pensamentos ecológicos, igualmente narcísicos: tratase da nostalgia de si mesmos, enquanto ironicamente trocam coices nos espaços sociais, cuja dimensão é formatada para intermináveis conflitos, subsumidos à paz para a qual todos dizem se voltar.

Atualmente, observo frequentemente comentários os quais são elaborados como apologias às tecnologias enquanto forma de emancipação antropológica. E isto no tocante a uma série de questões. Algumas dessas apologias têm estrita relação com a ecologia enquanto discurso político, (o de um desenvolvimento sustentável, por exemplo) que intenta dar guarida ao mundo com argumentos econômicos, científicos e amorosos interpenetráveis, os quais promovem lacrimosa piedade compassiva, com a finalidade de atribuírem soluções 


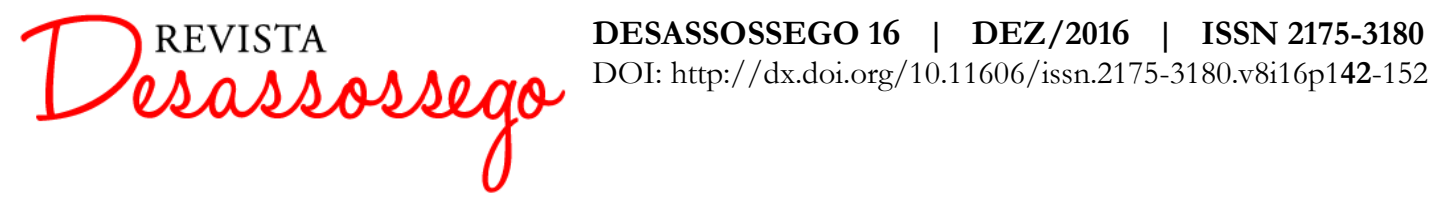

contra o estupro ao mundo por meio de uma tomada de decisão que parte exclusivamente do próprio homem. Tomada de decisão que clama, vocifera para que deliberações estritamente humanas continuem ocupando a cátedra das próprias deliberações políticas sobre o porvir de cada um dos organismos de um planeta que deveria recuperar seu "equilíbrio interno", o balanço harmônico que deveria lhe travestir como música de ninar, a qual teve sua melodia interrompida por cada um de nós.

Como não perceber o caráter absurdo e promiscuamente risível disto que o pensamento ecológico-político supracitado, os animais políticos de Aristóteles, intenta elaborar como solução? Nosso personagem, o mundo isento de bem e mal nas suas irrupções, apenas poderá ser salvo quando realmente for o sujeito ativo de suas deliberações. Ele não peticiona representações que se pensam a ele parcialmente exteriores. Advoga em nome próprio. Como já disse, o intuo como em estado de espera continente, ávido para nos esmagar a astuta inteligência através das formas mais cruéis, mesmo que para isto tenha de amputar de sua natureza alguns de seus elementos, como a água que também bebemos, o clima flexível que nos acolhe, alimentos os quais possamos absorver etc.

Nosso personagem, o qual paradoxalmente nos elencou como parceiros para essa tarefa, não desfalece no compasso em que intenta cumpri-la. Apenas arrancará, fará extraviar os subsídios que dão aporte a anomalia que ele mesmo teve a conativa audácia de plasmar enquanto horrenda figura estética: nós mesmos. Os ecologistas supramencionados e que dizem sofrer compassivamente com as dores do mundo anunciado, sejam ou não vegetarianos ou herbívoros, são estritamente hominídeos com sede de economia-política, cuja incapacidade para honestidade está à altura mesma da rapacidade, da cleptomania. Eis o maior de seus atributos, o que lhe confere designação mais adequada à empresa na qual, de corpo e alma, mergulham e se lambuzam. São incapazes de coerência, pois sua compaixão planetária se segue apenas ao limite do penhasco de uma covarde argumentação implícita: a da autopreservação lucrativa, a partir da qual podem olhar de forma monárquica para a totalidade da vida.

Preservar o planeta para garantir a perpetuação dos homens como espécie é no fundo uma brincadeira de mau gosto, um blefe, no mínimo um modo de tergiversar, caso queiramos, enfim, observar o mundo retomar o poder sobre o leme de sua audaciosa narrativa. Não tenhamos medo de afirmar que só pode tomar para si o movimento de sua 


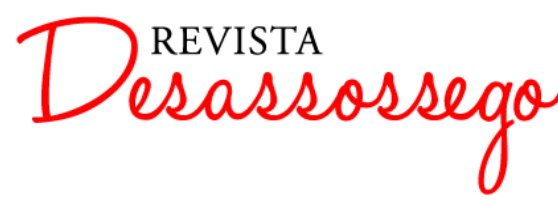

DESASSOSSEGO 16 | DEZ/2016 | ISSN 2175-3180

DOI: http://dx.doi.org/10.11606/issn.2175-3180.v8i16p142-152

história quando realmente terminar de executar seu grande empreendimento: arrancar de si mesmo alguns de seus elementos constituintes, até enfim não fazer sobrar um homem sequer - a não ser aquele que se prestará não mais à esbórnia cidadã, mas à função de adubo para distintos modos de vida, menos audazes na autodepravação.

Esta autodepravação, plasmada na peculiar forma de homem, arrasta a inteireza do que dela se diferencia para os recônditos da inexistência. Assim sendo, nenhum modo de tecnologia humanamente concebido é atualmente capaz de rearticular sob sua estrita responsabilidade um mundo menos insalubre. Somos insalubridade, e o mundo operar-se-á num dissenso com os frêmitos e colapsos vertiginosos os quais, hoje em dia, lhe ocupam inteiramente a estrutura. A forca está posta no âmago. Assim, o mundo portar-se-á como morcego o qual irá como fenda, mesmo desorientado perante humana luz, de encontro à carcaça dos que se dizem homens. Tal morcego, que ao fim também será abutre, fará então contrapartida, para não se deixar apossar, enfim, pelo espírito de um grande trauma.

Creio que sejamos uma experiência de mundo errada, e qualquer tentativa de superar os erros por meio da democratização das tecnologias é, sem sombra de dúvidas, não a salvação do planeta, mas a tentativa de fazer o mundo escorrer ainda mais aceleradamente no vácuo das impossibilidades criativas. Parece que, com nossas técnicas contemporâneas, entramos tão a fundo nas estruturas processuais assentadas no âmago do mundo que, de modo macabro, chegamos ao ponto de falsear a própria natureza desses processos estruturantes. Isso não é fazê-lo (o mundo) decidir percorrer os próprios caminhos atrozes que lhe servem enquanto narrativa da própria vida. Muito pelo contrário, estamos fingindo respeitá-lo, ao passo que adentramos com excêntricos bisturis naquilo que, ao fundo, apenas intenta operar na paz de uma guerra natural, e não na guerra humana, empresa cujo anúncio é um horizonte em que, ao ser tocado, permanece irreconhecível à paz. Ora, isso significa uma catástrofe completa para nós que, acreditandonos como lúdicos espertalhões divinos somados aos fanatismos sectários das belicosas crenças dos deuses multiculturais, não percebemos o que realmente está em operação: a vendeta do mundo, que, por enquanto, ainda reconsidera, poupa-nos. Graças a Deus!, dizem alguns dos piores tipos, histriônicos e dissimulados.

E quanto à linguagem como tecnologia? O que poderemos dela esperar? A denúncia, o delato do fato de que a narrativa do mundo ainda está à espera, para se deixar contar, para se deixar plasmar juntamente aos feixes que serão seus personagens. Atores de 


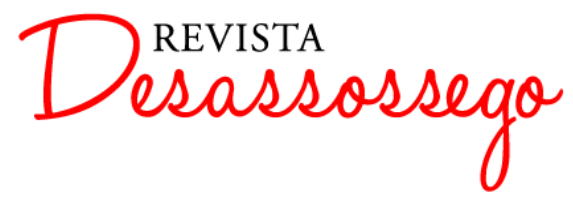

DESASSOSSEGO 16 | DEZ/2016 | ISSN 2175-3180

DOI: http://dx.doi.org/10.11606/issn.2175-3180.v8i16p142-152

um novo palco, o qual não pode mais ser ocultado, entregue às nossas mãos e discursos de conveniência, convenientes apenas conosco, conquanto expressos na forma de ardilosas eticidades (atrocidades).

A linguagem é uma das esferas da realidade, e não algo que dela se distancia, como muitos acreditam, fazendo apologia ao fragmentário da diversidade de opiniões unidimensionais para justificar a autoconservação das identidades mórbidas, frequentemente flexíveis, que lhes pertence. É também da natureza da realidade - dentro e fora das instituições sociais público-privadas - ser linguagem, embora, decerto, a isso ela não se reduza. A produção de discursos que seguem do pensar como autocompreensão de si e para si é uma das camadas da realidade, e não uma oposição a ela, e não uma simples tecnologia de poder, conquanto possa também o ser. Não é, portanto, necessariamente uma arma de guerra contra esta realidade, mas um aliado, porquanto, não sem determinada tensão, o real nos discursos se diferencie como espécie de autoimagem plural, democrática e não belicosa.

Os homicídios em massa nas duas grandes guerras mundiais não foram gerados pela linguagem que se pensa como uma das esferas da realidade em devir, mas por tecnologias de dominação disjuntivas, inclusive culturais e estéticas, subsidiadas no fundo pela necessidade de intensificação da venda de armas, do espólio de matérias-primas do globo terrestre e da injunção paralela destinada aos redimensionamentos na ordem mundial econômica e política. Por conseguinte, o que entra em jogo nas duas grandes guerras pode ser demarcado justamente pela incapacidade de se fazer um uso factual daquilo que caracteriza a linguagem em seu próprio movimento de autocrítica e diatribe do social, reencontrandose com o devir de um mundo escondido que a acompanha como lhe sendo realmente fraterno.

É justamente em função disso que podemos [re]avaliar nossa conduta psicofísica em face desse mesmo real, que não significa estritamente organização social, mas matéria em devir a qual pode ser interpelada contra o próprio enrijecimento ou falta de devir de uma organização asfixiantemente opressora econômica, política e socialmente. Avaliar nosso corpo e nossa estrutura subjetiva em meio aos espaços organizacionais significa, portanto, precisamente dar vazão a uma das camadas da realidade viva com a qual convivemos dentro de nós. Não se trata aqui de uma prática de autocontrole, mas gesto de se despir do eu margeado no entorno do dissimulado campo de crueldade que se quer como verdadeiro 


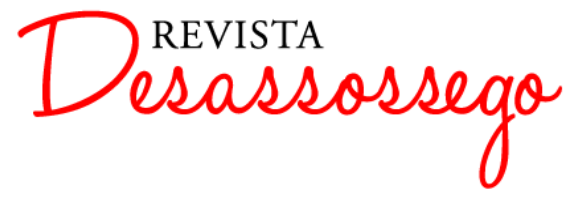

DESASSOSSEGO 16 | DEZ/2016 | ISSN 2175-3180

DOI: http://dx.doi.org/10.11606/issn.2175-3180.v8i16p142-152

mundo, conquanto a realidade do próprio planeta seja por esse "mundo" que a sonega negada pela premissa da depredação do vivo em sua totalidade.

O tratamento para com a linguagem é passível de se deixar transferir aos fluxos do mundo, cujo ser em devir clama pelo seu dizer. Dispor a linguagem à serviço deste ser é permiti-lo ser autor de vozes numa peça por ele dirigida, exprimindo vibração e recortando a biosfera, por fim comunicando aquilo que, aos ouvidos humanos, é demasiadamente estranho, conquanto singular. Um pássaro e o recorte de seu canto, é como, por exemplo, o mundo aufere enquanto exigência um ritmo melódico especial. De nossa parte, para não mais deixarmos o mundo à espera de um som, que pudesse de cada um de nós honestamente emanar, poderíamos atinar para o fato de que nossa língua tem o poder de não apenas abrigar a versão duma única voz, dissimulada na forma de pluralismo antropomórfico, recoberta por códigos que apenas conservam a [im]potência identitária das nossas artimanhas. Ao invés de estarmos acuados, em estados que margeiam a retidão do egoísmo, o que no fundo é o cinismo do tremor prazeroso que possui seu complemento antagônico na depressão como patologia contemporânea, poderíamos [re]colocar nossos espasmos metafísicos-individualistas na trincheira de uma linguagem a qual contra cada um de nós seria capaz de guerra, à medida que é passível de envolver o planeta com múltiplos abraços.

Aqui, trata-se não só de intentar superar uma falsa noção de história, que é real apesar de parcial, mas nos colocar à serviço de uma segunda narrativa, diferenciada em sinais peculiares, que apreendem o sentido do planeta. Uma narrativa de mundo, cujo sentido toma em alta conta os desdobramentos do planeta, propõe-se a reconstruir o modo como a própria história deste planeta, há tempos, tem sido encabeçada por um fio condutor que opera como uma política das humanas ilusões. Nesta enfeitiçada forma de poder, conclamam a si uma bazófia ideal que falseia a real história e processos vitais de mundo ao tomá-los como sendo iniciados num marco zero equivocado (até a teoria do Big Bang é excessivamente humana, porque resguarda inconscientemente a imagem anterior de um Deus homem, ou seja, o pano de fundo do acontecimento expresso enquanto exórdio do nosso universo). Por conseguinte, dimensionam a posteriori essa história na largada teleológica das disputas antropológicas de tribos que avançam no compasso das suas respectivas artes de vanguarda, desenvolvendo seus sujeitos, que galgam os passos na 


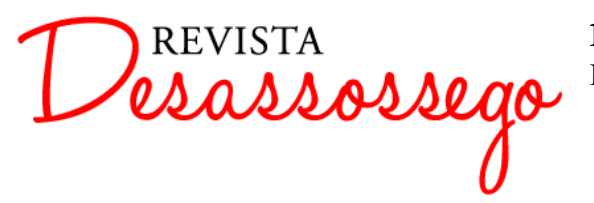

DESASSOSSEGO 16 | DEZ/2016 | ISSN 2175-3180

DOI: http://dx.doi.org/10.11606/issn.2175-3180.v8i16p142-152

direção evolutiva, retilínea embora sofrida, da autonomia humana. Assim, não observam os profundos retrocessos dos quais até os poros e odores estão agora impregnados.

A linguagem pode suplantar os gestos dessa autonomia absolutista que, ainda nos dias de hoje, se quer como intocável movimento histórico. É apenas outra narrativa de mundo que pode [re]colocar para si a linguagem nos eixos de seu sentido: é porvir o qual passa a ser cantado à medida que admite que o canto composto no presente expresso em seu nome é apenas uma das músicas de inacabado repertório. Esse repertório, por conseguinte, não é um reconto de fatos passados que prestam sem qualquer discrição homenagens repetitivas aos que se intitulam como protagonistas do planeta, que, acostumados a deste modo se aperceberem, avançam sobre o restante das coisas para nelas tatuar, bombardear a autoimagem homóloga às fantasiosas descobertas de momento. Trata-se aqui de outra coisa, de distinto repertório, deixemos isso bem claro.

O repertório em questão não é aqui mobilizado como reconto do mito do homem, um passado que se propaga sobre a Terra de acabrunhante maneira, oprimindo toda uma estrutura impessoal que neste mito deveria estar subsumida. O repertório que aqui defendo não está na nossa história, tal como numa pinacoteca humanista aonde poderíamos nos admirar com o que fomos e nos tornamos. Muito pelo contrário, o repertório ao qual me refiro é aquele que, sob a força da linguagem, ainda está por ser lançado como potência nominal de um mundo voraz, que se utiliza de sua fisionomia, e apenas dela, para uma narrativa contar. Por isso, a linguagem não deve ser instrumento do homem, tal qual homologia especular de sua natureza, pois deve assumir a missão de dele desacoplar, reposicionando-se às exigências da vida porvir, que não pode estar mais sob a tutela das imagens que a antropologizam. Temos de deixar esgotar as últimas fagulhas da autoimagem perversa que atribuímos a nós mesmos com tanta paixão. A linguagem do homem não pode ser confundida com os devires do mundo. Todavia, este mundo está à espera de outras línguas, de outra semântica.

O defunto ainda está vivo, apenas à espera, como já dissemos. É tempo, enfim, de deixá-lo contar para cada um de nós sua real história. Seríamos humildes para tanto, ou, d'outra maneira, continuaremos sendo o último suspiro humano em Terra, à repetição dos ofegantes simulacros dos particulares causos, faíscas autodestrutivas e reatualizáveis que, agregadas a pálidas velas, poderão, enfim, observar com lividez melancólica as chamas derradeiras? 


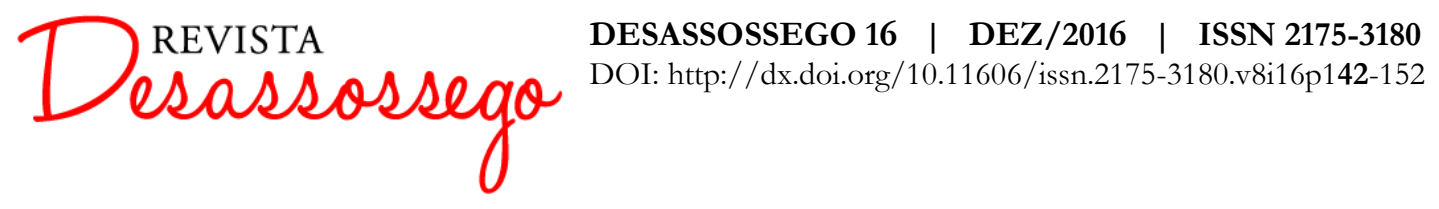

Ainda podemos nos deixar ser mundo, para não só o mundo se contar, mas para não sermos duplamente destruídos fisiologicamente, tanto pelo próprio planeta aparentemente acuado (que nos aplicará certamente a vendeta que há tempos merecemos), quanto pela autoimagem humana que constituímos como verdade absoluta a nosso [des]respeito e que, enfim, produzirá em definitivo o espaço social ideal, talhado para nos deglutirmos às dentadas caninas mais brutais. Este é o preço que pagaremos por continuar sendo tão humanos, como já diziam alguns escritores na passagem do século XIX para o XX? Será justamente este o coroamento, o desfecho dramático de um enfeitiçado descalabro do qual estamos possuídos? 